\title{
Fabrication of a flow channel for the production of polymer composite bipolar plates through hot compression molding
}

\author{
M.Y M. Yusuf ${ }^{1}$, M.Z. Selamat ${ }^{1}$, J. Sahari ${ }^{1}$, M.A M. Daud ${ }^{1}$, M. M. Tahir ${ }^{1}$ and \\ H.A Hamdan ${ }^{1}$
}

${ }^{1}$ Centre of Advanced Research on Energy (CARe), Faculty of Mechanical Engineering, Universiti Teknikal Malaysia Melaka, Hang Tuah Jaya, 76100 Durian Tunggal, Melaka, Malaysia

${ }^{2}$ Department of Mechanical and Materials Engineering

Faculty of Engineering and Built Environment

Universiti Kebangsaan Malaysia 43600 Bangi, Selangor, Malaysia

*Email: zulkeflis@utem.edu.my

\begin{abstract}
Materials used to fabricate polymer electrolyte membrane fuel cell (PEMFC) bipolar plates need to be light, strong, cheap, easily fabricated, mechanically stable, and have low surface contact resistance. Additionally, the performance of PEMFCs is greatly influenced by the materials used, flow channel design and shape to be fabricated on the bipolar plate surface. In this study, the fabrication of a flow channel through the hot compression molding method was developed. All materials used were in powder form, with graphite $(\mathrm{G})$, carbon black $(\mathrm{CB})$ and ferum $(\mathrm{Fe})$ as fillers, and polypropylene (PP) acting as binder. The ratio of fillers $(\mathrm{G} / \mathrm{CB} / \mathrm{Fe})$ to binder $(\mathrm{PP})$ was fixed at 80:20. The fillers ratio was fixed in the range of (25 to $65 \mathrm{wt} \%) \mathrm{G},(10$ to $30 \mathrm{wt} \%) \mathrm{CB}$ and (5 to 25 wt $\%)$ Fe, and all fillers were mixed using a ball mill machine. The second stage of the mixing process involves the mixing of fillers and a binder, which was mixed using a internal mixer machine. Subsequently, the compaction process through hot compression molding was carried out. During the hot compression molding process, the flow channel of serpentine type, and $\mathrm{U}$ or $\mathrm{V}$ shapes were pressed onto the surface of the sample. The in-plane electrical conductivity and mechanical properties such as flexure strength, bulk density and shore hardness were then measured. Thus, a flow channel was investigated for accuracy of surface condition of flow channel dimensions (using a coordinate measurement machine), and subsequently compared with the actual drawings and its process ability. Based on electrical conductivity, flexure strength, bulk density and shore hardness, the sample with $15 \mathrm{wt} \%$ Fe was shown to yield the best results of $137.39 \mathrm{~S} / \mathrm{cm}^{3}$, $34.04 \mathrm{MPa}, 1.582 \mathrm{~g} / \mathrm{cm}^{3}$, and 53.14 respectively. Meanwhile, based on the analysis of flow channel dimensions, the $\mathrm{V}$ shape is shown to give a smooth surface, with a dimensions difference between samples and the drawing of about -0.118 to $0.27 \%$. Meanwhile, for the process ability, the $\mathrm{V}$ shape is much easier to release from the mold. In summary, this study revealed that the flow channel with $\mathrm{V}$ shape can be fabricated through the hot compression molding method with high accuracy.
\end{abstract}

Keywords: Graphite; bipolar plate; electrical conductivity; polymer electrolyte membrane fuel cell. 


\section{INTRODUCTION}

The polymer electron membrane fuel cell (PEMFC) is an electrochemical device that converts chemical energy directly into electrical energy, with heat and water additionally generated in this reaction. As the capacity of fuel cells to produce energy increases, the amount of heat and water produced per unit volume also increases. Consequently, the thermal management of fuel cell stacks has become an important issue [1-4]. PEMFCs produce zero emissions and are scalable. Moreover, they offer high power densities and fast start-up. The bipolar plate is one of the components that contributes significantly to the total PEMFC manufacturing cost [5]. Conducting polymer composites (CPC) as bipolar plates are an attractive alternative to pure graphite and metal bipolar plates. CPCs have the capability to provide the necessary properties such as electrical and thermal conductivity while offering good mechanical strength to support the forces within the stack, even at a reduced plate thickness [6-8]. Nonetheless, the properties of CPC must meet the DoE target as shown in Table 1. Materials widely used in CPCs include graphite $(\mathrm{G})$, carbon black $(\mathrm{CB})$, carbon nanotube (CNT) and carbon fibre (CF). For metal fillers, iron (Fe) and stainless steel (SS) are used, and for the binder, polypropylene (PP) and epoxy [9-11] are commonly used. CPCs have also been widely used as bipolar plates in laboratory-scale research due to the fact that they are moderate conductors to electricity, lightweight, resistant to corrosion, and can produce precise flow-field channels. Additionally, the processing and manufacturing methods also influence the final properties of a composite bipolar plate on the dispersion, orientation and inter-particle distance within the resin or matrix. [12-15] reported that the molding process also can alter the aspect ratio of conductive fillers, enhance the interaction with the matrix and change the degree of crystallinity of the matrix. The performances of PEMFC are also dependable on the types of materials used, flow channel design and shape that have been fabricated on the bipolar plate surface. Currently, the flow channel is fabricated on the surface of the bipolar plate through a machining process, which is too expensive and time consuming $[5,10,16,17]$. In relation to this, a flow channel can be molded directly onto the bipolar plate surface during the fabrication process by using hot compression molding, thereby eliminating the costly and difficult machining steps required in the fabrication of the flow channel. Previous researchers [5] found that the usage of the machine for the fabrication machining is not suitable for flow channel shaping, especially for very detailed dimensions, as it vibrates and its plunging speed is too high. Once the flow channel machining process is completed, bur formation is observed in abundance. This is a risk if machining is not properly run during the process. By comparing the current technique and possible equipment, the fabrication of flow and cooling channels through the compression molding method is an attractive alternative because it requires less time, less tools set up and less monitoring. However, the drawback of this method is that it may only be suitable for fabricating flow and cooling channels with simple designs and shapes.

\section{Serpentine Type Flow Channel}

In the single serpentine flow channel, several studies [2] have examined the impact of the channel cross section area, channel width/height ratio, and/or the ratio between channel width and rib width on PEMFC performance. However, none of the studies referred to the design off-set from the manufacturing process. The serpentine type flow channel is shown in Figure 1. In this task, two draft angles were selected based on the bipolar plate manufacturing reports. It is noted that the draft angle of zero or each factor of infinity is equivalent to the typical cross section shape obtained from the laboratory graphite plate 
made using a machining process. Figure 2 shows the fabrication of a flow channel using hot compression molding for $\mathrm{U}$ and $\mathrm{V}$ shapes. As the draft angle is increased from $0^{0}$ to $33.7^{0}$, the sample becomes easier to release from the mold. However, the drawback is that the performance of the bipolar plate will be reduced [5]. Meanwhile, according to Figure 2, the V shape is more suitable [18]. The other important factor that needs to be considered is the geometry of difference shape must have with same area, as shown in Figure 3.

Table 1. Properties required by PEMFC bipolar plates $[9,10,19]$.

\begin{tabular}{lc}
\hline \multicolumn{1}{c}{ Property } & Value \\
\hline Electrical conductivity & $>100 \mathrm{~S} / \mathrm{cm}$ \\
Weight & $<0.4 \mathrm{~kg} / \mathrm{kW}$ \\
Flexural strength & $>25 \mathrm{MPa}$ \\
Flexibility & $3-5 \mathrm{deflection}$ at mid-span \\
Thermal conductivity & $>10 \mathrm{~W} /(\mathrm{mk})$ \\
Gas permeability & $<2 \times 10^{-6} \mathrm{~cm}^{3} \mathrm{~cm}^{-2} \mathrm{~s}^{-1}$ at $80^{\circ} \mathrm{C}$ \\
Corrosion resistance & $<1 \mu \mathrm{Am}^{-2}$ \\
Bulk Density & $<5\left[\mathrm{~g} / \mathrm{cm}^{3}\right]$ \\
\hline
\end{tabular}

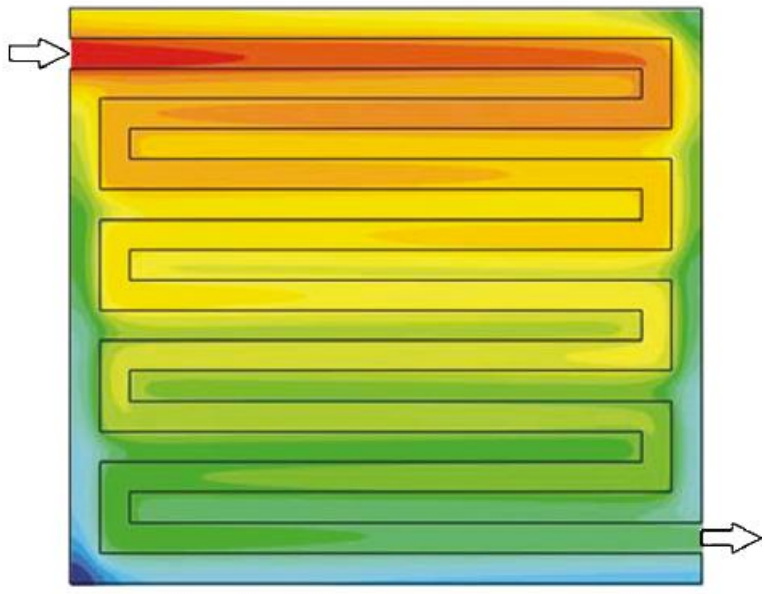

Figure 1. Serpentine type flow field showing the concentration of oxygen in the gas diffusion layer [10].

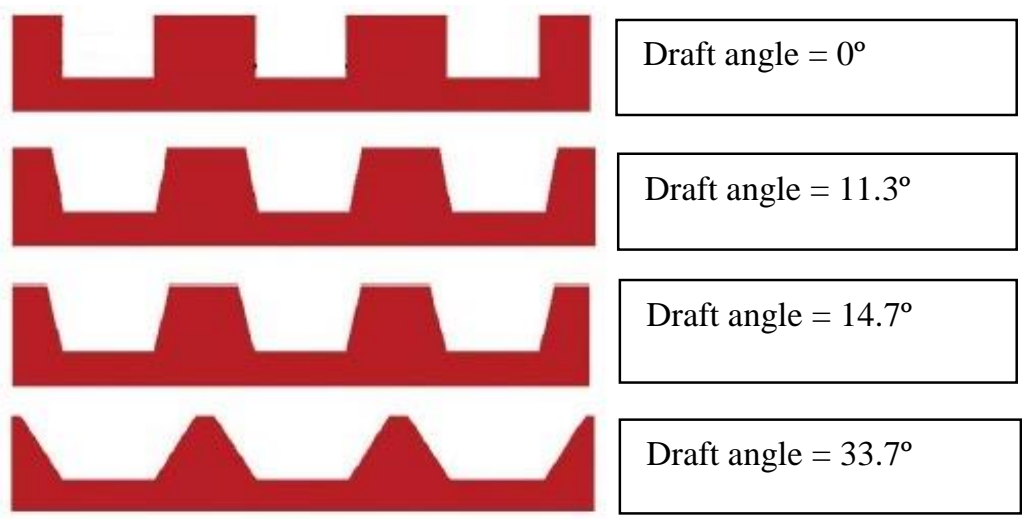

Figure 2. Geometry of difference draft angle [5]. 


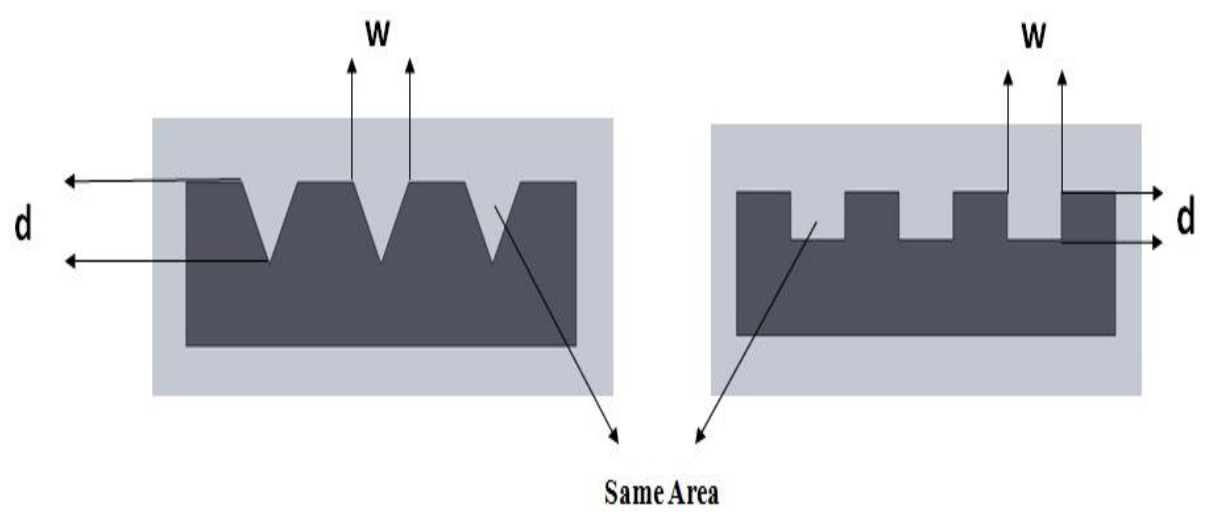

Figure 3. Geometry of difference type with the same area.

Thus, the main concern of this research is to determine the effects of different flow field channels based on geometrical dimensions such as the number of channels, width size, depth size, rib area and draft angle. The flow channel shapes to be fabricated are the serpentine type flow field and parallel type flow field. The main filler materials to be used in this project are graphite $(\mathrm{G})$, carbon-black (CB), polypropylene (PP) and iron $(\mathrm{Fe})$. The objective of this study is to investigate the flow channel fabrication of a multifiller $\mathrm{G} / \mathrm{CB} / \mathrm{Fe} / \mathrm{PP}$ composite through the compression molding method such as the surface condition, flow channel dimensions (used coordinate measurement machine) and it's process ability.

\section{METHODS AND MATERIALS}

\section{Fabrication of Polymer Composites}

Five loading ratios of $\mathrm{G} / \mathrm{CB} / \mathrm{Fe} / \mathrm{PP}$ composite were produced by compression molding and Figure 4 shows all of the materials that have been used. The compositions of $\mathrm{G} / \mathrm{CB} / \mathrm{Fe} / \mathrm{PP}$ are shown in Table 2 . All the fillers of $\mathrm{G} / \mathrm{CB} / \mathrm{Fe}$ were mixed using a ball mill machine for one and a half hours to attain homogenous mixtures. After that, G/CB/Fe/PP mixtures were further mixed using a Haake Poly lab Rheodrive Internal Mixer machine at a temperature of $200^{\circ} \mathrm{C}$ and a rotor speed of $50 \mathrm{rpm}$ for 15 minutes. After the compounding process was complete, the mixture was collected and pulverized to further refine the specimens as some of them agglomerate and form lumps. This process was done using a Retsch ZM200 Pulverizer.
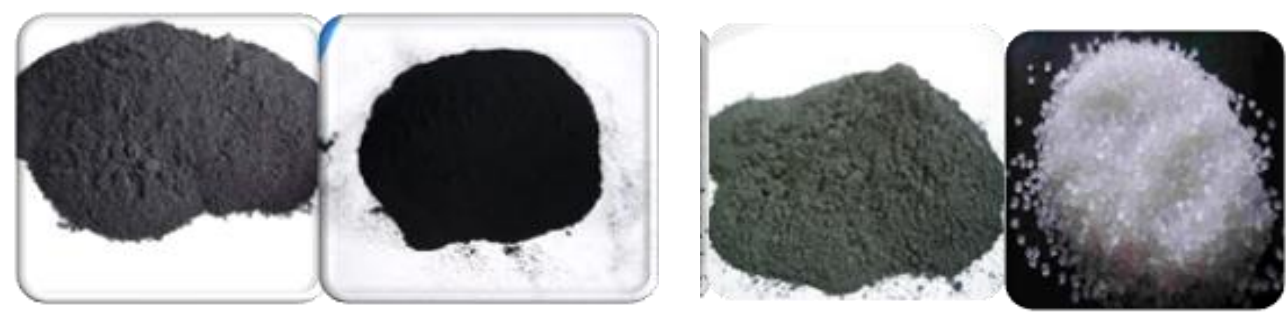

Figure 4. From left - graphite, carbon black, iron ferum, and polypropylene.

The next step was to form a bipolar plate specimen. The compression molding method was chosen to shape the sample. This process was done using the Gotech (GT 
7014 - A) hot press machine. Before the compression process starts, the temperature should be set to $185^{\circ} \mathrm{C}$. After that, the mold was placed in the hot press machine. The preheating time takes about 10 minutes after the heating process is done. The pressure was then set at 5 tons and the pressing time was 10 minutes. The mold was then removed from the hot press space and carefully placed in the cold press space. The duration of the cooling time was about 15 minutes and after that the specimen was removed from the mold.

Table 2. G/CB/Fe/PP composition (based on weight \%).

\begin{tabular}{ccccc}
\hline Number & $\begin{array}{c}\text { Graphite } \\
\%\end{array}$ & Carbon Black \% & $\begin{array}{c}\text { Ferum } \\
\%\end{array}$ & $\begin{array}{c}\text { Polypropylene } \\
\%\end{array}$ \\
\hline 1 & 65 & 10 & 5 & 20 \\
2 & 55 & 15 & 10 & 20 \\
3 & 45 & 20 & 15 & 20 \\
4 & 35 & 25 & 20 & 20 \\
5 & 25 & 30 & 25 & 20 \\
\hline
\end{tabular}

\section{Equipment for Testing Electrical Conductivity and Mechanical Properties}

This test was carried out to determine the electrical conductivity of the bipolar plates. It was conducted using a Jandel Multiheight Microposition probe. The conductivity measurements of the samples were done by the four point probe technique using a Jandel four point probe head. According to DoE requirements, the electrical conductivity of bipolar plates must be more than $100 \mathrm{~S} / \mathrm{cm}^{3}$. Figure 5 shows the apparatus and the method employed for taking the measurement.

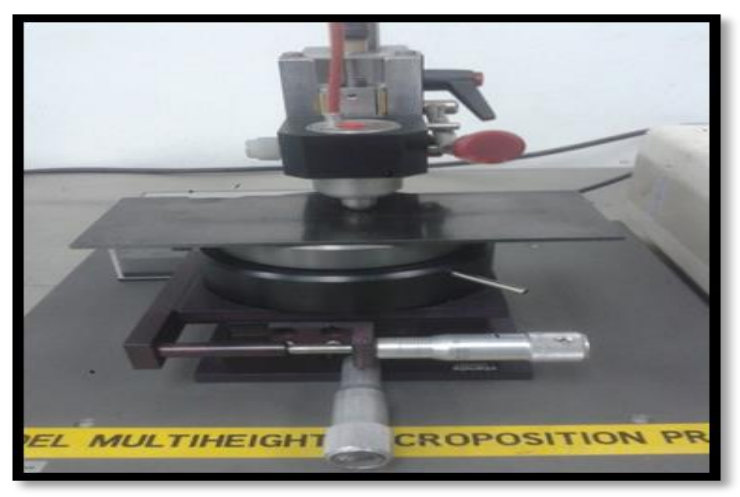

Figure 5. Jandel Multiheight Microposition Probe.

The flexural test is one of the most important tests to be carried out as flexural strength defines the failure limit of the bipolar plate. This test was done using an INSTRON Universal Testing Machine. The plates were cut into $130 \mathrm{~mm} \times 13 \mathrm{~mm}$ pieces before testing. The machine is as shown in Figure 6. This test is one of the Standard Test Methods for Flexural Properties of Unreinforced and Reinforced Plastics and Electrical Insulating Materials (ASTM D 790 - 03). The density test is important for making sure that the bipolar plate is lightweight. This test was carried out using an electronic densimeter. According to DOE requirements, the density of the bipolar plate must be less than $5 \mathrm{~g} / \mathrm{cm}^{3}$ to reach the 2017 target. Figure 7 shows the Electronic Densimeter. This test 
is one of the Standard Test Methods for Density and Specific Gravity (Relative Density) of Plastics by Displacement (ASTM D792). Shore hardness measures the hardness of a material. This test was carried out using an analogue TECLOCK GS -702G Shore-D Durometer. Figure 8 shows the analogue Durometer. This test is one of a Standard Test Method for rubber property - Durometer hardness (ASTM D2240D).

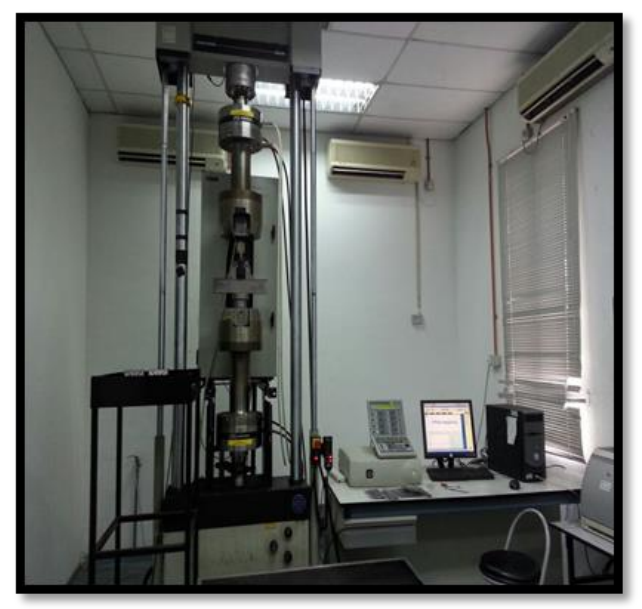

Figure 6. INSTRON universal testing machine.

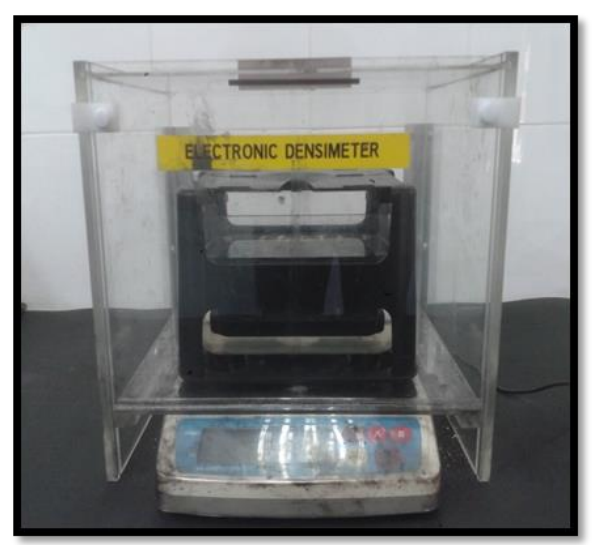

Figure 7. Electronic densimeter.

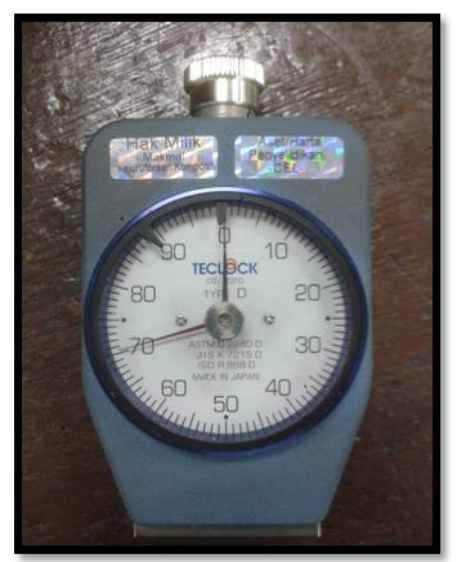

Figure 8. Analogue TECLOCK GS -702G shore-D durometer. 


\section{Fabrication of Flow Channel through Hot Compression Molding}

After the hot compression molding of the five samples was complete, several property tests were done on one of them. Usually, the sample which gives the best electrical and mechanical properties will be selected. Subsequently, the next process is the fabrication of a flow channel through hot compression molding with $U$ shape by using two types of draft angle flow channels $\left(0^{\circ}\right.$ and $\left.30^{\circ}\right)$. Figure 9 shows the mold part and Figure 10 shows the shape of the $0^{\circ}$ draft angle and $30^{\circ}$ draft angle.

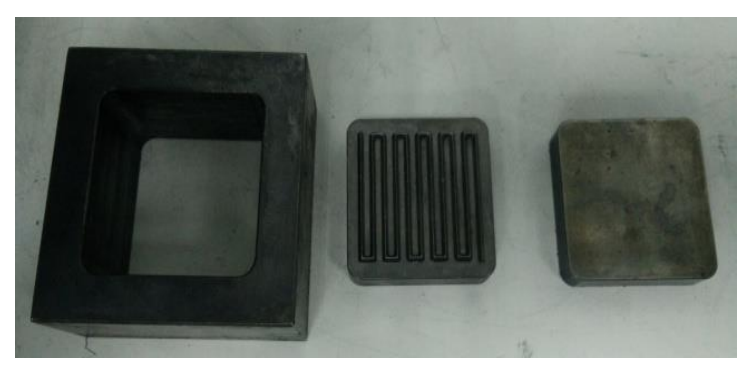

Figure 9. Body and centre part mold flow channel serpentine $(50 \mathrm{~mm} \times 50 \mathrm{~mm})$.

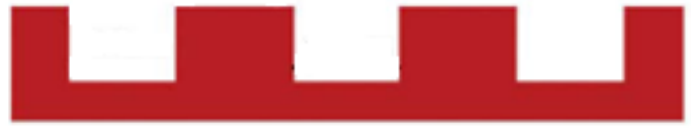

(a)

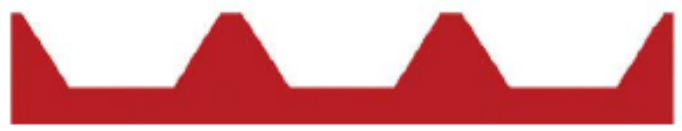

(b)

Figure 10. (a) Draft angle $0^{\circ}$ and (b) Draft angle $30^{\circ}$.

\section{Drawing Design Process}

The drawing design process involves the setting of important geometric parameters for the flow channel. The design of the flow channel is then drawn using CAD software. Table 3 shows the main parameters of the flow channel design to be machined at the mold centre part. Figure 11 shows the solid work drawing for a mold with a flow channel. After the flow channel was mechanized at the surface of the centre part, the fabrication of the flow channel through compression molding was undertaken. Furthermore, the analysis of the fabrication process, physical properties and dimensions of the flow channel were determined.

Table 3. Parameters of flow field design for flow channel mold.

\begin{tabular}{lc}
\hline \multicolumn{1}{c}{ Parameters of flow channel } & Mold \\
\hline Dimension & $50 \mathrm{~mm} \times 50 \mathrm{~mm}$ \\
Type of flow channel & U Long parallel \& V Long parallel \\
Flow channel Array & 16 \\
Width of flow channel & $1.5 \mathrm{~mm}$ \\
Depth of flow channel & $0.5 \mathrm{~mm}$ \\
Taper angle of flow channel & $30^{\circ}$ \\
Thickness of plate & $3 \mathrm{~mm}$ \\
\hline
\end{tabular}




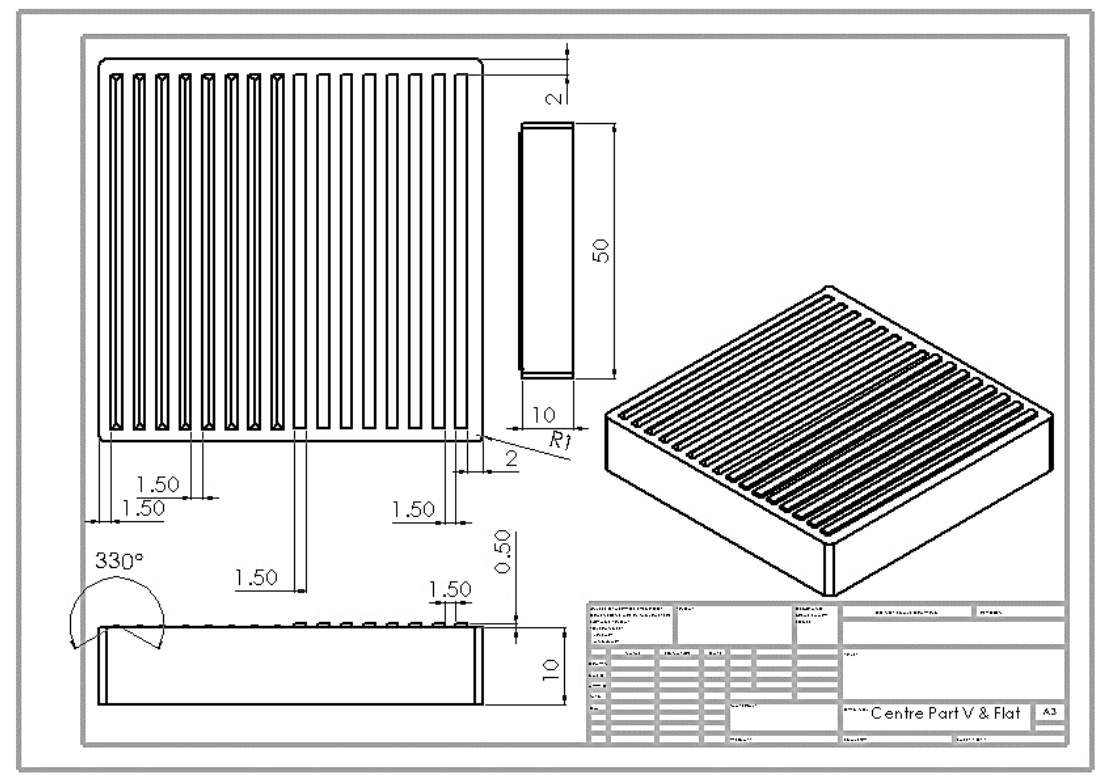

Figure 11. Complete drawing using CAD software.

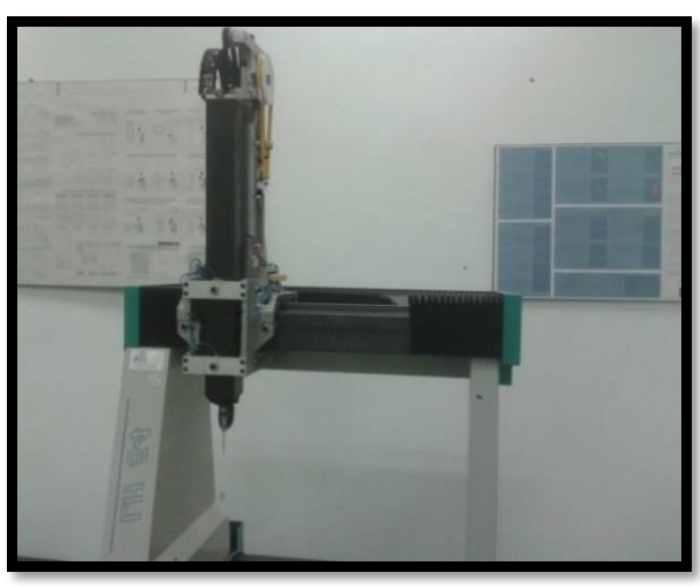

Figure 12. Coordinate measuring machine.

\section{Coordinate Measurement Test}

A coordinate measurement test is done to measure the physical characteristics (dimensions) of an object. This test was done using the Coordinate Measuring Machine smart scope CNC500. Coordinate measuring systems (CMSs) determine dimensional (length-based) characteristics of mechanical parts by analysing 3-dimensional point data acquired on part surfaces. Data analysis software can contribute significantly to the total measurement error of a CMS. Factors affecting software performance include the choice of analysis method, the quality of software implementation, and characteristics of the specific measurement task [11, 20]. Figure 12 shows the Coordinate Measuring Machine used in this study.

\section{RESULTS AND DISCUSSION}

\section{Electrical Conductivity and Mechanical Properties}

Figure 13 and 14 show the electrical conductivity and flexural strength of G/CB/Fe/PP composites. The results show that the increase in Fe content also increases electrical 
conductivity. Additionally, the maximum value of electrical conductivity was shown by the sample with $20 \% \mathrm{Fe}$ content of about $158.6 \mathrm{~S} / \mathrm{cm}$. Small Fe particles increase the conductivity between $\mathrm{G}$ particles. This increases the electrical conductivity of the samples [9-11]. Beyond a $20 \%$ content of Fe, the electrical conductivity of the sample decreased because there are less conducting tunnels between $\mathrm{G}$ practical and the lower conductivity, contributed by sample of $5 \%$ Fe content with the value of $96.21 \mathrm{~S} / \mathrm{cm}[10,11,16]$. All the electrical conductivity values met the DOE requirement, which is about $>100 \mathrm{~S} / \mathrm{cm}$ accepted at $5 \% \mathrm{Fe}$ content. Meanwhile, the increase in Fe content decreases the flexural strength from 41.7 to $21.1 \mathrm{MPa}$ at $25 \% \mathrm{Fe}$ content. The sudden surge in flexural strength is observed because of the adhesive bonding between fillers and binder which decreased as Fe content increased [10]. All the values of flexural strength met the DoE requirement which is about $>25 \mathrm{MPa}$ accepted for $5 \%$ Fe with a value of $21.11 \mathrm{MPa}$.

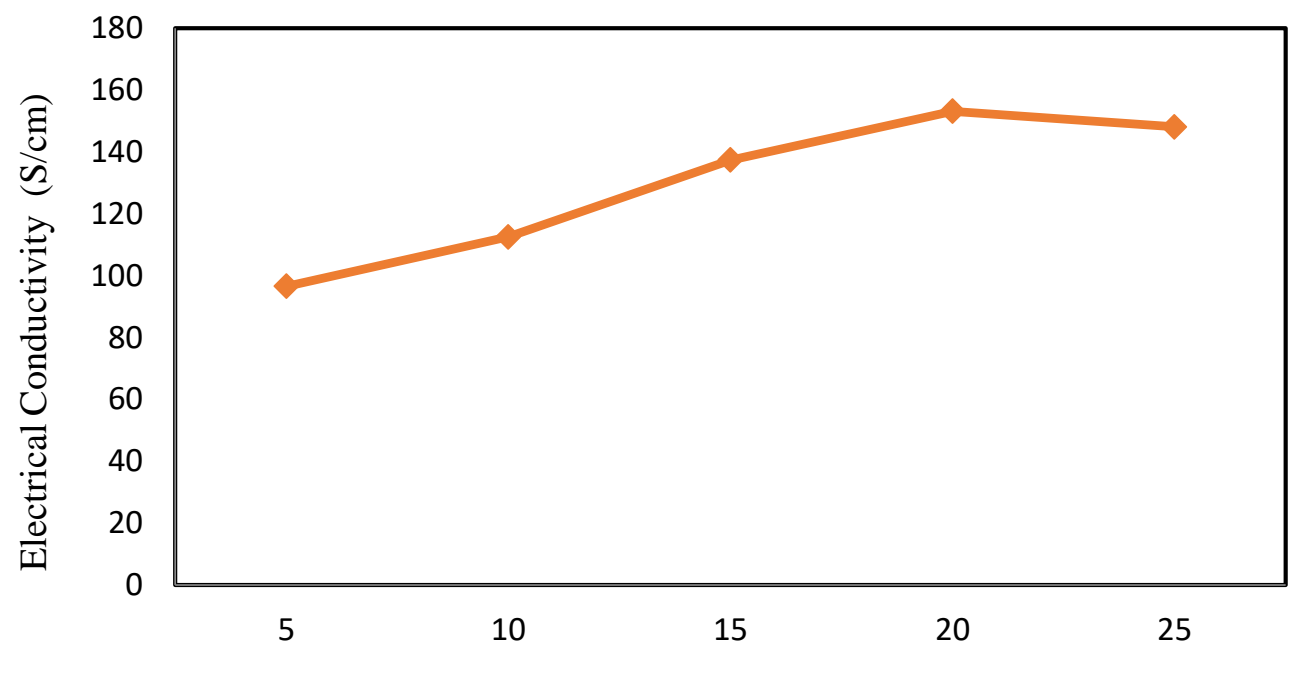

Fe Content (wt $\%)$

Figure 13. The variation of electrical conductivity.

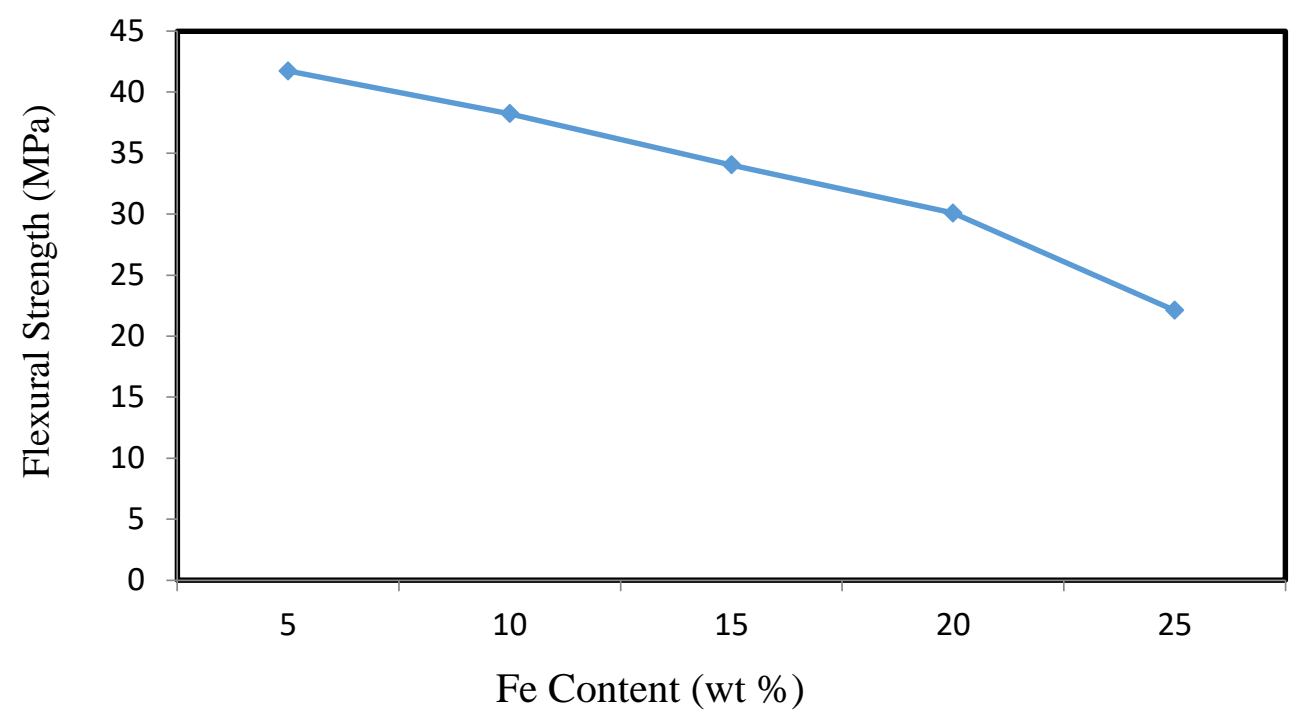

Figure 14. The variation of flexural strength. 


\section{Bulk Density and Shore Hardness}

Figures 15 and 16 show the bulk density and shore hardness of the G/CB/Fe/PP composite. For bulk density with an additional Fe content, the density of the sample decreased. The value decreased from $1.589 \mathrm{~g} / \mathrm{cm}^{3}$ at $5 \mathrm{wt} \%$ to $1.578 \mathrm{~g} / \mathrm{cm}^{3}$ at $10 \mathrm{wt} \%$. For the next sample, the value of bulk density increased from 1.578 at $10 \mathrm{wt} \%$ to 1.586 at $25 \mathrm{wt} \%$. The density of all compositions complied with the standard set by DoE (target 2017) which states that the density must be less than $5 \mathrm{~g} / \mathrm{cm}^{3}$ [10]. However, the shore hardness of the composite decreased with an increase in Fe content. The value of shore hardness decreased from 55.83 at $5 \mathrm{wt} \%$ to 51.43 at $25 \mathrm{wt} \%$ Fe content. The decrease in hardness of the composite can be attributed to the poor bonding of $\mathrm{Fe}$ contents with other constituents in the composite $[10,11]$. Based on the electrical and mechanical properties of the five samples of $\mathrm{G} / \mathrm{CB} / \mathrm{Fe} / \mathrm{PP}$ composite, the sample with a composition of $45 / 20 / 15 / 20$ (G/CB/Fe/PP) showed the best electrical and mechanical properties. In addition, all of the properties met the DoE target $[13,16]$. Therefore, this composition was selected to be used in the fabrication of a flow channel using hot compression molding.

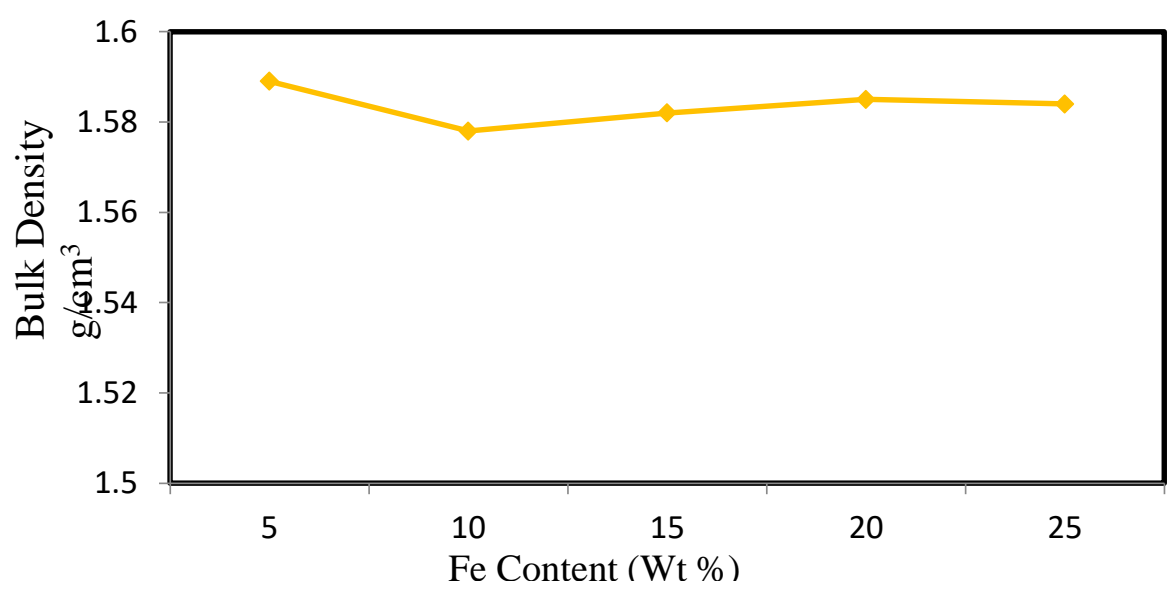

Figure 15. Graph of density test.

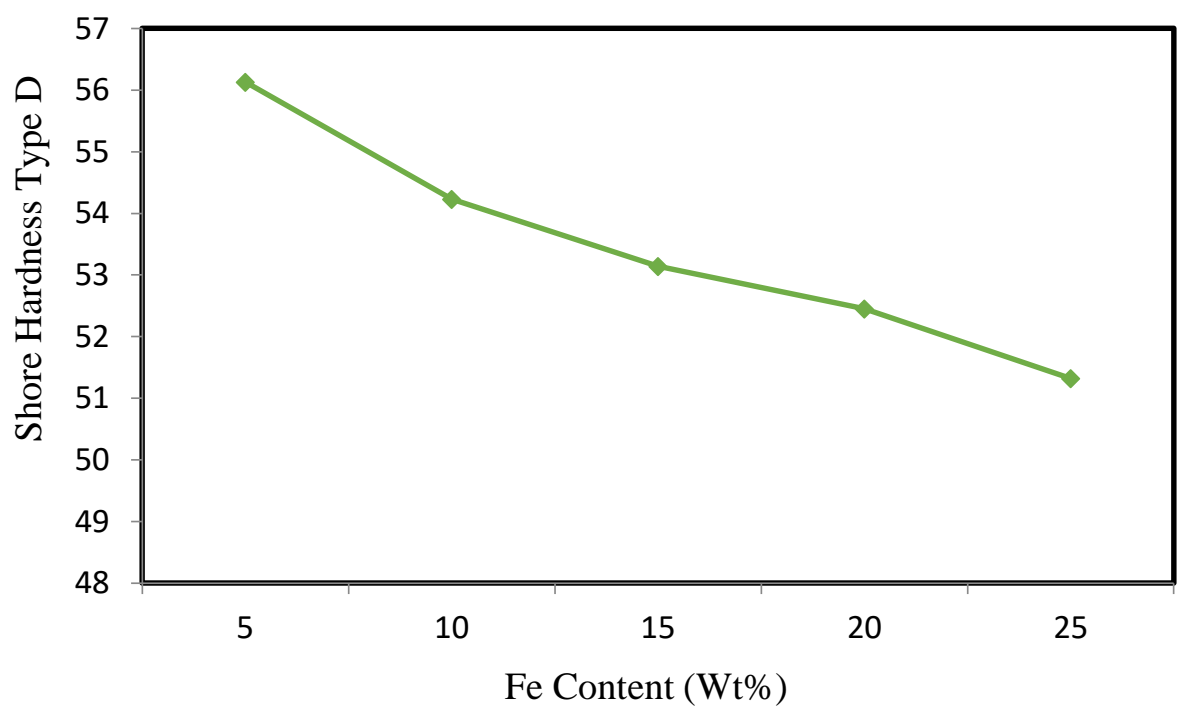

Figure 16. Graph of shore hardness. 


\section{U Shape Flow Channel}

Several trials were made to fabricate a U-shape flow channel with $0^{0}$ and $30^{\circ}$ draft angle through hot compression molding. Figure 17 (a) shows the center part of the mold with a $\mathrm{U}$ shape flow channel. The first attempt used $100 \%$ polypropylene (PP). The second attempt used G/CB/Fe/PP composite. Meanwhile, Figure 17 (b) shows the samples that have been fabricated in the flow channel through hot compression molding. The results show that about $100 \%$ PP produced good surface conditions for the sample. Additionally, for the $\mathrm{G} / \mathrm{CB} / \mathrm{Fe} / \mathrm{PP}$ composite, the sample was found to be cracked and broken. Thus, the $\mathrm{U}$ shape needed a suitable draft angle for process ability. This is especially so for a $0^{0}$ draft angle whereby the sample broke due to the draft angle being $0^{\circ}$. It is also difficult to be removed from the center part $[5,10]$.

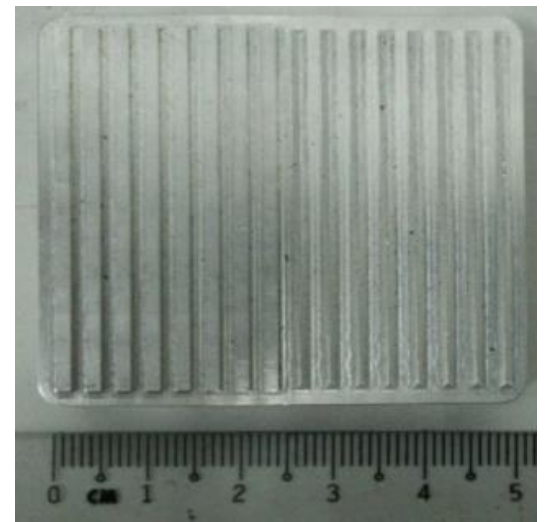

(a)

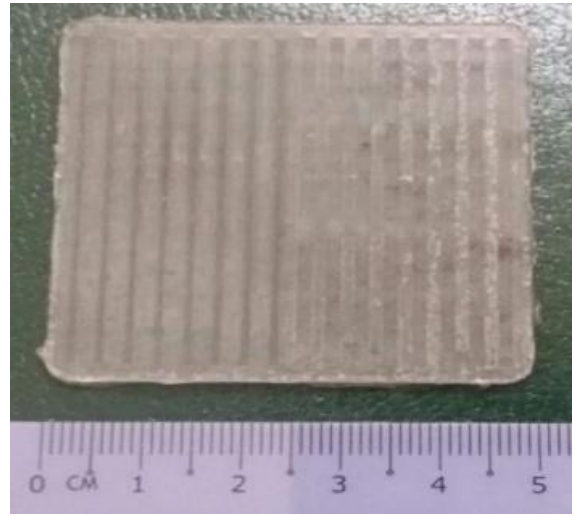

(b)

Figure 17. (a) Centre part mold and (b) PP sample with U shape flow channel with a draft angle of $0^{\circ}$ and $30^{\circ}$ parallel flow channel.

For a draft angle of $0^{0}$, it was shown that it was too difficult to release the composite material sample (G/CB/Fe/PP) from the center part. Moreover, it also sticks to the surface. However, for the draft angle of $30^{\circ}$, the sample can be more easily released from the center part. Therefore, the bigger the draft angle, the easier it is to be released $[5,10]$. Meanwhile the surface of the sample is rough and in some parts has flaked out.

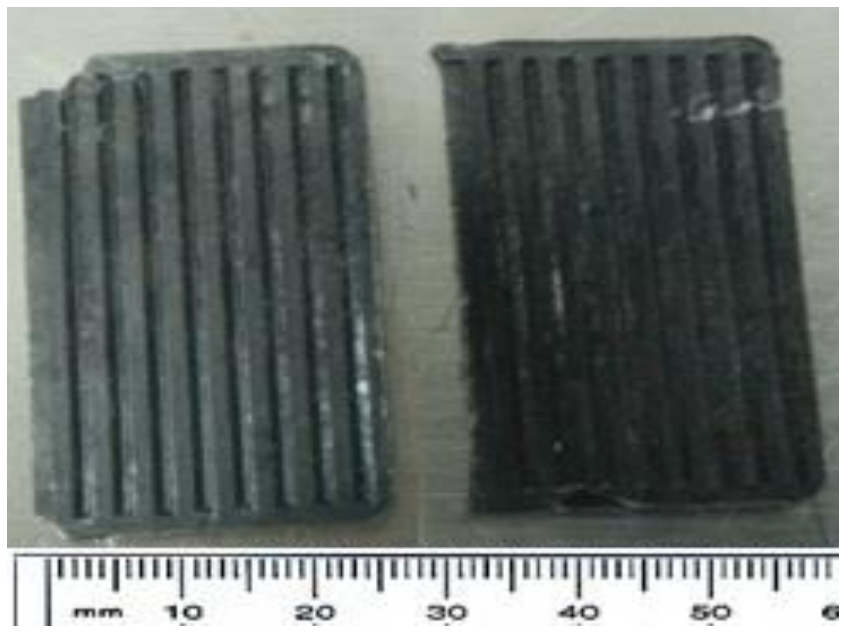

Figure 18. G/CB/Fe/PP composite sample for a $\mathrm{U}$ shape flow channel with a draft angle of $0^{0}$ and $90^{\circ}$ that has broken and cracked. 
Based on the results with the U shape flow channel, some modifications have been made. The U shape was changed to a $\mathrm{V}$ shape with a draft angle of $30^{\circ}$. The draft angle is fixed at $30^{\circ}$. An advantage of this draft angle is that the sample can more easily be released from the center part. Figure 19 shows the CAD drawing of the modifications.

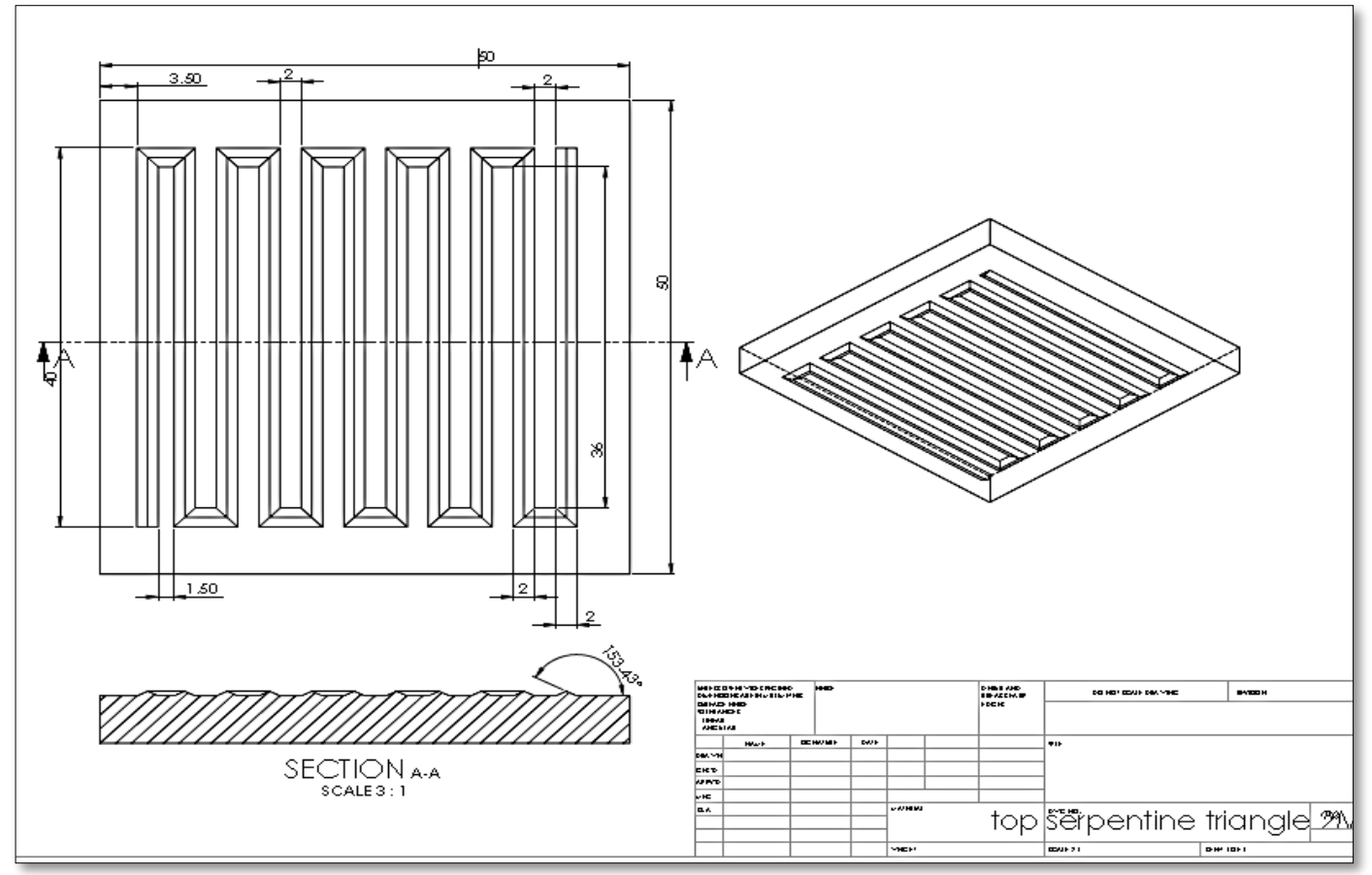

Figure 19. CAD drawing for center part mold serpentine $30^{\circ}$.

\section{Shape Flow Channel}

Figure 14 shows the sample that has been fabricated using a V shape flow channel. It shows that the shape of the flow channel and surface of the sample have accurately formed. Several measurements have been conducted to compare the dimensions of the points indicated in Figure 20 with the actual CAD drawing.
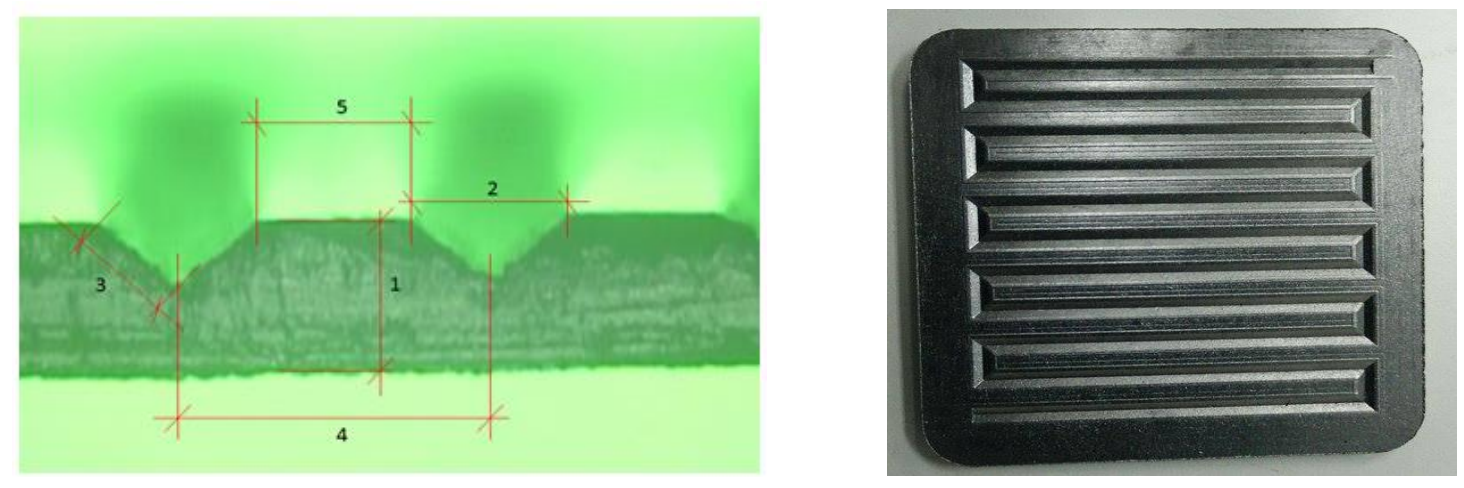

Figure 20. Fabricate dimensions and indication of points where the measurement was taken and their respective pair.

A comparison was also made between the $\mathrm{U}$ shape with a $0^{\circ}$ draft angle and the $\mathrm{V}$ shape with a $30^{\circ}$ draft angle. In terms of the fabrication process for the $\mathrm{V}$ shape, the 
sample can more easily be released from the mold surface. The surface of the sample is also smoother and is unbroken, with no portion of the sample having flaked out.

\section{Coordinate Measurement Test}

The measurements of each point dimension of the plate were taken in pairs. Figure 20 shows the indication of measurement points with their respective pair. Table 4 shows the dimension data of the flow channel for $\mathrm{G} / \mathrm{CB} / \mathrm{Fe} / \mathrm{PP}$ compositions respectively and the difference with size drawing and fabricate dimension. The results show a comparison of drawing and fabricating dimension (No 1 to No 5). As shown, the difference is slightly smaller and the percentage is in the range of -0.118 to $0.27 \%$. Therefore, the result is nearly similar to the dimension of drawing with the fabricated. Meanwhile, as compared with the U shape of the flow channel, the dimensions (No 1 to No 5) cannot be measured because the sample was cracked and broken. This happened due to the process ability of the U shape compared to the $\mathrm{V}$ shape during the hot compression process. For the U shape with a $0^{0}$ draft angle, the sample was broken and is difficult to remove from the center part $[5,10]$.

Table 4. Difference drawing and fabricate dimensions.

\begin{tabular}{ccccc}
\hline No & Drawing $(\mathrm{mm})$ & Fabricate $(\mathrm{mm})$ & Different & Different \% \\
\hline 1 & 1 & 1.118 & -0.118 & $-0.118 \%$ \\
2 & 1.5 & 1.473 & 0.027 & $0.27 \%$ \\
3 & 0.870 & 0.862 & 0.008 & $0.08 \%$ \\
4 & 3 & 2.985 & 0.015 & $0.15 \%$ \\
5 & 1.5 & 1.48 & 0.02 & $0.02 \%$ \\
\hline
\end{tabular}

\section{CONCLUSIONS}

Overall, this study has contributed to our knowledge about the fabrication of flow channels using the hot compression molding method. Based on the electrical and mechanical properties of five samples of $\mathrm{G} / \mathrm{CB} / \mathrm{Fe} / \mathrm{PP}$ composite, the sample with $45 / 20 / 15 / 20$ (G/CB/Fe/PP) composition showed the best electrical and mechanical properties, all of which met the DoE target. Meanwhile, based on the findings of serpentine, for $\mathrm{U}$ and $\mathrm{V}$ shape flow channels made of $\mathrm{G} / \mathrm{CB} / \mathrm{Fe} / \mathrm{PP}$ composite with 15 wt $\%$ of $\mathrm{Fe}$, the latter showed better finishing and formability of the flow channel. The coordinate measuring tested showed that the average percentage of difference between the drawing and fabricated dimension of the G/CB/Fe/PP plate was in the range of -0.118 to $0.27 \%$. The lower percentage of difference in dimension of the G/CB/Fe/PP plate shows better formability, accuracy and quality. For future studies, this method should be used to fabricate larger bipolar plates and the fabricated flow. Additionally, the V shape cooling channel should also be tested as a single stack performance.

\section{ACKNOWLEDGEMENTS}

The authors would like to thank the Malaysia Ministry of Higher Education, Malaysia and Ministry of Science, Technology and Innovation for sponsoring this work under Grant (FRGS(RACE)/2013/FKM/TK2/2 F00203) Faculty of Mechanical Engineering and Universiti Teknikal Malaysia Melaka (UTeM). 


\section{REFERENCES}

[1] Chiang HL, Feng TL, Su A, Huang ZM. Performance analysis of an open-cathode PEM fuel cell stack. Advanced Materials Research: Trans Tech Publ; 2014. p. 630-4.

[2] Jindal P, Jyoti J, Kumar N. Mechanical characterisation of ABS/MWCNT composites under static and dynamic loading conditions. Journal of Mechanical Engineering and Sciences. 2016;10:2288-99.

[3] Abdullah HZ, Idris MI, Harun Z, Ismail AF, Yunos MZ, Hasan S. Influence of polyethylene glycol additive on performance of polysulfone and polyethersulfone membrane. Journal of Mechanical Engineering and Sciences. 2014;6:746-52.

[4] Mohamed WANW, Atan R. Polymer electrolyte membrane fuel cell. International Journal of Automotive and Mechanical Engineering. 2012;5:648-59.

[5] Shimpalee S, Lilavivat V, Van Zee JW, McCrabb H, Lozano-Morales A. Understanding the effect of channel tolerances on performance of PEMFCs. international journal of hydrogen energy. 2011;36:12512-23.

[6] Merajul Haque M, Hasan M. Mechanical properties of betel nut and glass fibre reinforced hybrid polyethylene composites. International Journal of Automotive and Mechanical Engineering. 2016;13:3763-72.

[7] Kasim AN, Selamat MZ, Daud MAM, Yaakob MY, Putra A, Sivakumar D. Mechanical properties of polypropylene composites reinforced with alkaline treated pineapple leaf fibre from Josapine cultivar. International Journal of Automotive and Mechanical Engineering. 2016;13:3157-67.

[8] Fahmi I, Abdul Majid MS, Afendi M, Helmi EA, M. Haameem JA. Low-velocity impact responses of Napier fibre/polyester composites. International Journal of Automotive and Mechanical Engineering. 2016;13:3226-37.

[9] Ahmad MS, Selamat MZ, bin Daud MA, Yunus M, Kasuma I, Azman MS. Effect of different filler materials in the development of bipolar plate composite for polymer electrolyte membrane fuel cell (PEMFC). Applied Mechanics and Materials: Trans Tech Publ; 2013. p. 226-30.

[10] Selamat MZ, Ahmad MS, Daud M, Ahadlin M, Jusoff K. The hybrid conductive filler in the bipolar plate for polymer electrolyte membrane fuel cells. the hybrid conductive filler in the bipolar plate for polymer electrolyte membrane fuel cells. Australian Journal of Basic and Applied Sciences. 2013;7:72-7.

[11] Selamat MZ, Masron F, Yusuf M, Yusri M, Kamarolzaman AA, Tahir MM, et al. Effect of stannum on properties of graphite/stannum composite for bipolar plate. Applied Mechanics \& Materials. 2014;699.

[12] Krupa I, Chodák I. Physical properties of thermoplastic/graphite composites. European Polymer Journal. 2001;37:2159-68.

[13] Chodak I, Omastova M, Pionteck J. Relation between electrical and mechanical properties of conducting polymer composites. Journal of Applied Polymer Sciences. 2001;82:1903-6.

[14] Banerjee P, Mandal BM. Conducting polyaniline nanoparticle blends with extremely low percolation thresholds. Macromolecules. 1995;28:3940-3.

[15] Zakaria I, Michael Z, Mohamed WANW, Mamat AMI, Azmi WH, Mamat R, et al. A review of nanofluid adoption in polymer electrolyte membrane (PEM) fuel cells as an alternative coolant. Journal of Mechanical Engineering and Sciences. 2015;8:1351-66.. 
[16] Selamat MZ, Ahmad MS, bin Daud MA, Ahmad N. Effect of carbon nanotubes on properties of graphite/carbon black/polypropylene nanocomposites. Advanced Materials Research: Trans Tech Publ; 2013. p. 29-34.

[17] Othman R, Wilkinson A. The impedance characterization of hybrid cnt-silica epoxy nanocomposites. International Journal of Automotive and Mechanical Engineering. 2014;10:1832.

[18] Hung J-C, Chang D-H, Chuang Y. The fabrication of high-aspect-ratio microflow channels on metallic bipolar plates using die-sinking micro-electrical discharge machining. Journal of Power Sources. 2012;198:158-63.

[19] Adrianowycz O, Norley J, Stuart DJ, Flaherty D, Wayne R, Williams W, et al. Next generation bipolar plates for automotive PEM fuel cells. GrafTech International Holdings Ltd.; 2010.

[20] Diaz C, Hopp TH. Testing of coordinate measuring system software. 1993. 